\title{
STUDIES IN HYDRATION ENERGETICS OF NUCLEIC ACID COMPONENTS BY THE DIFFERENTIAL UV-SPECTROSCOPIC METHOD
}

\author{
V. A. Sorokin, V. L. Galkin, V. A. Valeev, E. S. Arkhipova, \\ G. O. Gladchenko, Yu. P. Blagoi \\ Institute for Low Temperature Physics and Engineering, \\ Academy of Sciences of the Ukrainian SSR, Kharkov
}

$\mathrm{Sum} m$ ary

Differentiai UV spectra of CMP, UMP, AMP, IMP, GMP and Guo are obtained, which are due to dehydration of these substances during heating of their aqueous solutions from 20 to $90^{\circ} \mathrm{C}$. The enthalpies and entropies of hydration characterizing the interaction between water molecules and heteroatoms of the base rings are calculated. The entropy term yreatly contributed to the variations of the free Gibbs energy for UMP, IMP, AMP, GMP a:d Guo. The enthalpy and entropy terms are comparable for CMP.

удк 577.122 .3

Т. Ј. Јевитина, Н. М. Гусак, Н. В. Роднин, М. Т. Кириленко,

о. С. Мирошниченко, С. А. Атепалихина, Ј. В. Гудкова, Э. А. Козлов

\section{БРОМЦИАНОВЫЕ ФРАГМЕНТЫ RATAJAЗЫ ГРИЕA PENICILlIUM VITALE}

Каталазу $P$. vitale расщепляли бромцианом. Гель-фильтрованием через сефадексы, ионообменной хроматографией на различных ионообменниках, экстракцией бутанолом и водньм бифером, высоковольтным әлектрофорезом ка бумаге выделекы девять фрагментов, насчитывающих в сумме 387 аминокислотных остатков (50\% полипептидной цепи белка). Исследовали N-концевье аминокислотные последовательности, триптические и химотриптические пептиды этих фрагментов. В результате установлена полная "нинск:іслотная пос.едовательность фрагмента, включающего 61 остаток аминокислот, " частіиная аминокислотная последовательность деух фрагментов, насчитываницх $в$ су.и.не 37 остаткое.

Настоянее сообщсние является продолжением серии публикаций, посвященных исследованию первичной структуры каталазы $P$. vitale. llepзые трп работы $[1-3]$ освешают результаты изучения триптических пептидов.

Материалы и методы. Расщепление белка бромцианом осуществляли по методу Гроссз и Виткопа [4]. 800 мг ( 10 мкM) каталазы и 100 мг триптофана растворяли в $50 \mathrm{k.?} ; 0$;-ной НСООН. Добавляли бромциан ( 500 мг в 2 мл НСООН), выдерживали $22:$ пюи комнатиой температуре в темноте и лиофилизнровали.

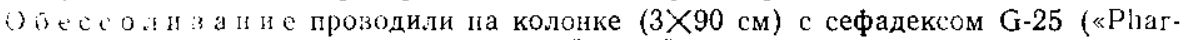
пасіа», Швеция), уравынепенным аммначной водой.

Ге егь-фильтров ан ие через сефадекс G-75 (грубый) («Pharmacia»). Растворители: а) 0,2 М трис-НCl-оуфер, рН 8,7, содержащий $6 \mathrm{M} \mathrm{Gu} \cdot \mathrm{HCl}$; б) $20 \%$-ная НСООН. Полученные фракции обессоливали.

Ио:ообмей ия хроматография. ДЭАЭ-сефадекс А-25 («Pharmacia»). Исходны: буфер: 0.025 $\mathrm{M}$ трис-НС!, $\mathrm{pH} 7.4$, содержащнй $6 \mathrm{M}$ мочевину. Линейный градиент: 150 мл исходного буфера и 150 мл этого же буфера с добавкой $0,4 \mathrm{M} \mathrm{KCl}$. Сульфопропил (SP)-сефадекс C-50 («Plrarmacia»). Исходный буфер: универсальная буферная смесь, pH 3,7 [5], содержащая $6 \mathrm{M}$ мочевину. Вогнутый градиент: 75 мл универсальнй буферной смеси, содержащей $6 \mathrm{M}$ мочевину, и 75 мл этой же смеси с добавкой $0,5 \mathrm{M} \mathrm{KCl.} \mathrm{Фракции,} \mathrm{полученные} \mathrm{ионообменной} \mathrm{хроматографией,} \mathrm{обессолива.ти.}$

Высокоэффективная жидкостная хроматография (ВЖKX). Прнменяли систему FPLC («Pharmacia»). Колонка моноQ. Исходный буфер: $0,02 \mathrm{M}$ трис$\mathrm{HCl}, \mathrm{pH} 7,4$. содержащ й $6 \mathrm{M}$ мочевину. Градиент создава.ли исходным буфером, содержащим $1 \mathrm{M}$ KС. Полученные фракции обессо:ива.ли.

экстракии ч бутано.том. Материал фракции растворя.ти в 50 мл $20 \%$-ной 
$\mathrm{HCOOH}$, насыщенной $н$-бутанолом. Қ раствору добавляли 25 мл н-бутанола, насыщенного $20 \%$-ной $\mathrm{HCOOH,} \mathrm{и} \mathrm{встряхивали.} \mathrm{После} \mathrm{разделения} \mathrm{суспензии} \mathrm{отбирали} \mathrm{три}$ фракции - бутанольную (Б), промежуточную (П) и водную (В). Полученные фракции упаривали на роторном испарителе.

Экстракция бу фером. Лиофильно высушенный материал фракции экстрагировали $0,025 \mathrm{M} \mathrm{Na-ацетатным} \mathrm{буфером,} \mathrm{pH} 4,5$, содержацим $0,1 \mathrm{M} \mathrm{NaCl}$. Осадок отделяли центрифугированием. Супернатант обессоливали.

В ысоковольтный электрофорез (B/B) на бумаге проводили в течение 1,5 ч при градиенте напряжения 40-60 B/см на приборе, сконструированном в Ин-те микробнологин и вирусологин АН УССР [6], в электролитах ЭФ1, рН 6,5 (пиридин : уксусная кислота: вода $(100: 4: 896))$, ЭФ2, pH 1,9 (муравьиная кислота: уксусная кислота : вода $(41,2: 10: 948,8))$. Бумага FN 17 («Filtrak», ГДР).

$\mathrm{Xpomaтография} \mathrm{на} 6$ умаге. Применяли систему БХ1 (пиридиг : бутанол : уксусная кислота: вода $(10: 15: 3: 12))$. Бумага та же, что и для электрофореза.

Эл ек т рофорез в полиакриламндном геле (ПААГ) проводити по методу, описанному в литературе [7].

Р асще пление трипсином и химотрипсином осуществляли, как описано ранее $[1,3]$.

II оследов ательность аминокислот определяли ручным методом Эдмана в сочетании с дансилированием [8] и на секвенаторе $890 \mathrm{C}$ («Beckman», CША) с последующей идентификацией PTH-амннокислот в системе HPLC («Pharmacia»).

Ам инокислотный состав определяли на анализаторе аминокислот AАA-331 (ЧССР). Пробы гидролизовали 5,7 н. НСl, содержащей $0,1 \%$ фенола, в течение 24 ч при $105-110^{\circ} \mathrm{C}$ в вакууме.

Результаты и обсуждение. Смесь бромциановых фрагментов разделяли на четыре фракции гель-фильтрованием через сефадекс G-75 (рис. 1). Для дальнейшего разделения каждой из фракций мы апробировали комбинации различных методов. В результате была выбрана схема, приводящая к оптимальным результатам (рис. 2). Цифрами или буквами в квадратных рамках обозначены фракции, полученные на каждом этапе и подвергнутые дальнейшему разделению, подчеркнутыми цифрами - фракции, содержащие минорные количества материала; дальнейшему разделению их не подвергали; латинскими буквами в рамках - N-концевые остатки аминокислот фракций, включающих от двух до пяти фрагментов (по числу N-концевых остатков). Эти девять фракций содержали такое количество материала, которое при

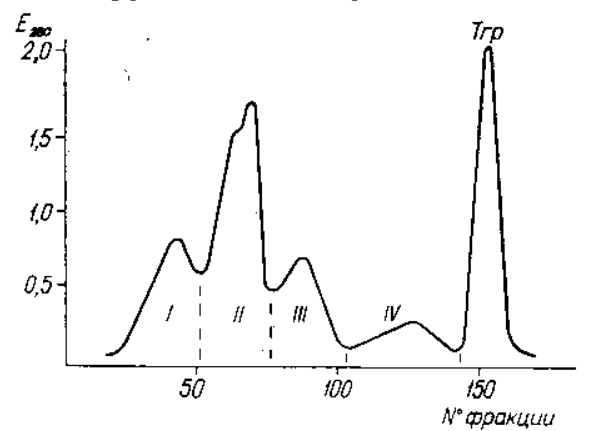

Рнс. 1. Разделение продукта (180 мг) расmепления бромцианом каталазы $P$. vitale на колонке $(2,2 \times 90 \mathrm{~cm})$ с сефадехсом $\mathrm{G}-75$, уравновешенным растворителем «а» («Материалы и методы»). Скорость элюции 15 мл/ч, объем фракцин 2,5 мл

Fig. 1. Separation of $P$. vitale catalase cyanogen bromide fragments on a column $(2.2 \times 90 \mathrm{~cm})$ with Sephadex G-75 equilibrated by $0.2 \mathrm{M}$ tris. $\mathrm{HCl}, \mathrm{pH} 8.7$ containing $6 \mathrm{M}$ Gu. HCl. Flow rate $-15 \mathrm{ml} / \mathrm{h}$, fraction volume $-2.5 \mathrm{ml}$

последующем разделении не давало бы высоких выходов индивидуальных фрагментов, необходимых для выяснения аминокислотной последовательности имеющейся техникой. Поэтому эти фракции далее не разделяли.

На рис. 3-6 представлены результаты разделения некоторых фракций на отдельных этапах схемы. В табл. 1 приведены аминокислотные составы полученных фрагментов. Лактон гомосерина на анализаторе амннокислот ААА-331 выходит одним пиком с гистидином. Поэтому в табл. 1 под гистидином понимается либо сам гистидин, либо лактон, либо их смесь. Гомосерин на анализаторе может элюироваться либо вместе с глутаминовой кислотой или с серином, либо самостоя- 


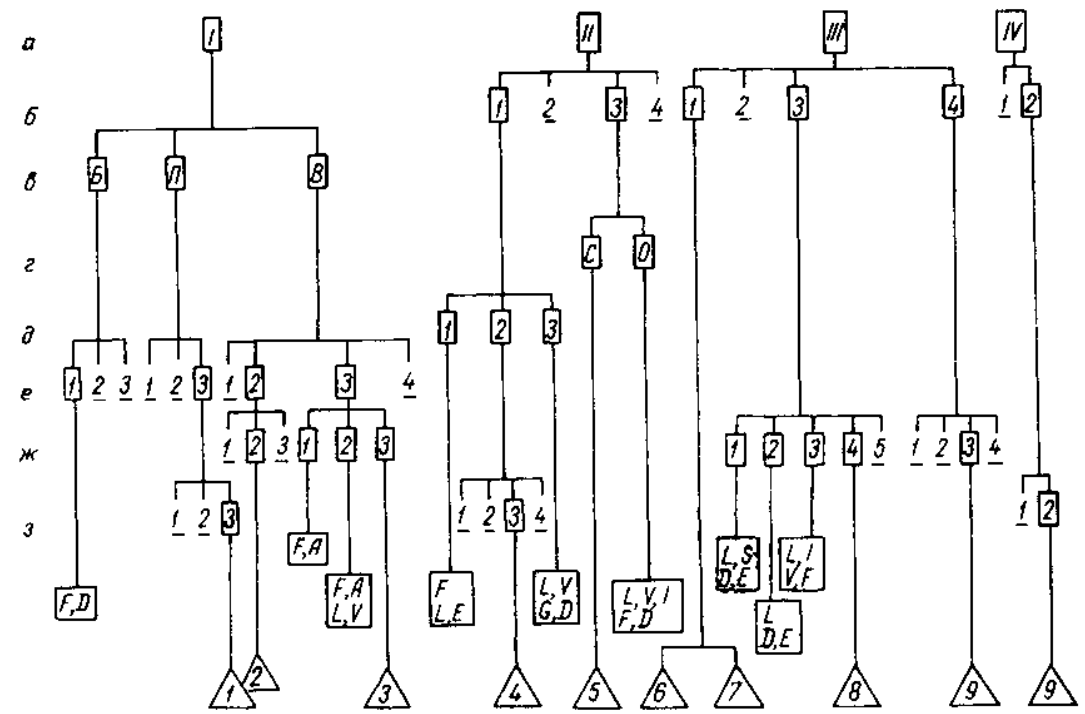

Рис. 2. Схема разделения бромциановых фрагментов каталазы P. vitale: G-75, $6 \mathrm{M}$ мочевина $(a)$; ДЭАЭ-сефадекс, $6 \mathrm{M}$ мочевина (б); экстракция бутанолом (8); экстракция буфером, $\mathrm{pH} 4,5$ (2); SP-сефадекс, $6 \mathrm{M}$ мочевина $(\partial)$; G-75, $20 \%$-ная $\mathrm{HCOOH}(e)$; FPLC, моноQ, $6 \mathrm{M}$ мочевина (ж); В/В электрофорез, pH 6,5 (3)

Fig. 2. Scheme of isolation of $P$. vitale catalase cyanogen bromide fragments: G-75, $6 \mathrm{M}$ urea (a); DEAE-sephadex, $6 \mathrm{M}$ urea (б); butanol extraction (B); buffer extraction, $\mathrm{pH} 4.5$ (e); SP-sephadex, $6 \mathrm{M}$ urea $(d)$; G-75, $20 \% \mathrm{HCOOH}(e) ; \mathrm{FPLC}$, monoQ, $6 \mathrm{M}$ urea $(\nVdash) ; \mathrm{B} / \mathrm{B}$ electrophoresis, $\mathrm{pH} 6.5(3)$
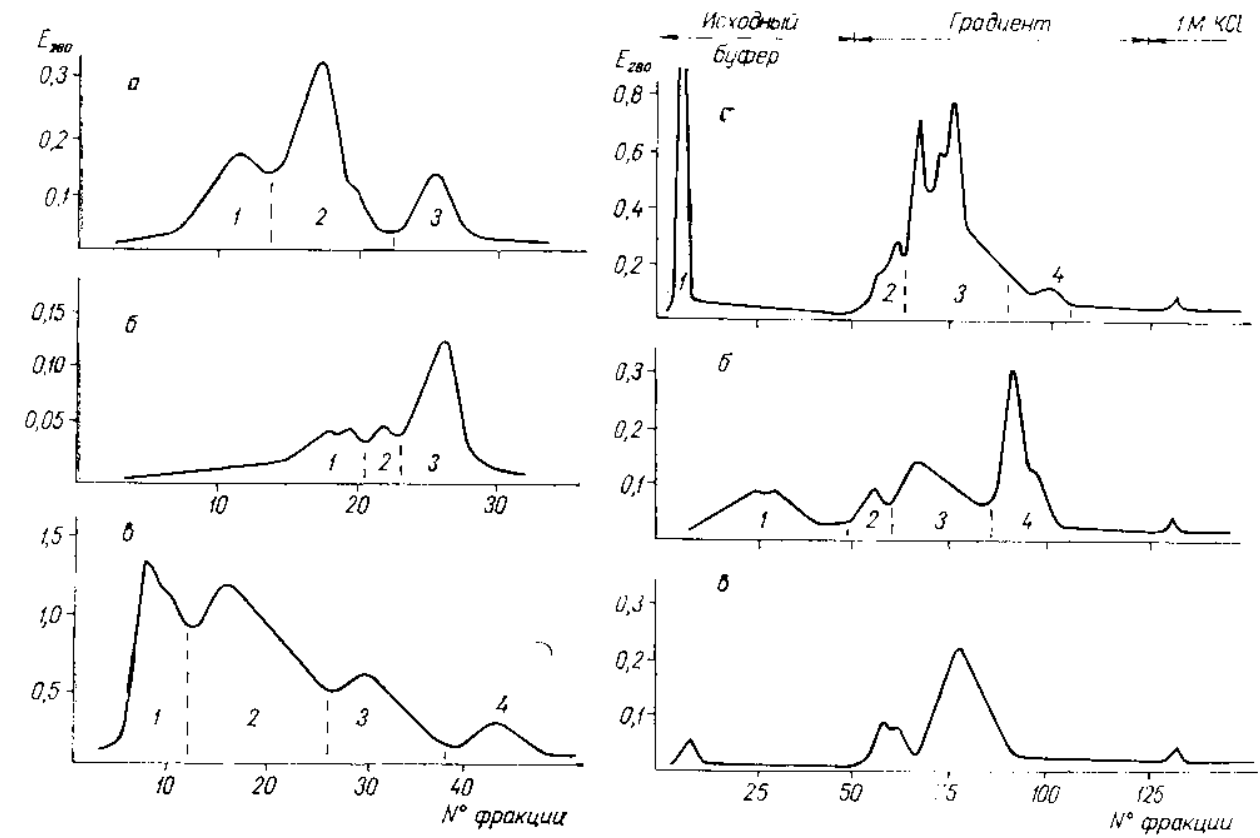

Рис. 3. Разделсние фракций І-Б (a), І-П (б) и І-В (в) рис. 2) на колонке $(2,2 \times$ $\times 90 \mathrm{cm)} \mathrm{с} \mathrm{сефадексом} \mathrm{G-75,} \mathrm{уравновешенным} \mathrm{растворителем} \mathrm{«б».} \mathrm{Скорость} \mathrm{элюции}$ 20 мл/ч, объем фракции 3 мл

Fig. 3. Separation of I-D $(a), \mathrm{I}-\Pi(\sigma)$ and I-B $(8)$ fractions (Fig. 2$)$ on a column $(2.2 X$ $\times 90 \mathrm{~cm})$ with Sephadex G-75 equilibrated by $20 \% \mathrm{HCOOH}$. Flow rate $-20 \mathrm{ml} / \mathrm{h}$, fraction volume $-3 \mathrm{ml}$

Рис. 4. Разделение фракций II $(a)$, III $(\sigma)$ и IV $(\beta)$ (рис. 1$)$ гі колонке $(1,4 \times 18 \mathrm{~cm}$ ) с ДЭАЭ-сефадексом А-25. Буфер и градиент см. «Материалы и методы». Скорость элюции 20 мл/ч, объем фракции 5 мл

Fig. 4. Separation of fraction II (a), III (6) and IV (B) (Fig. 1) on a column (1.4X $\times 18 \mathrm{~cm}$ ) with DEAE-sephadex A-25. Start-buffer: $0.025 \mathrm{M}$ tris. $\mathrm{HCl}, \mathrm{pH} 7.4$, containing $6 \mathrm{M}$ urea. Linear gradient $-150 \mathrm{ml}$ start-buffer and $150 \mathrm{ml}$ start-buffer containing $0.4 \mathrm{M} \mathrm{KCl}$. Flow rate $-20 \mathrm{ml} / \mathrm{h}$, fraction volume $-5 \mathrm{ml}$ 
тельно между ними. В приведенных фрагментах мы не смогли однозначно ндентифищировать гомосернн. Так как фрагменты BrCN6 и BrCN7 получены в смеси, аминокислотный состав BrCN6 выписан в табл. 1 на основании структуры этого фрагмента [9], установленной на смеск двух фрагментов. Зная аминокислотный состав фракции III-I,

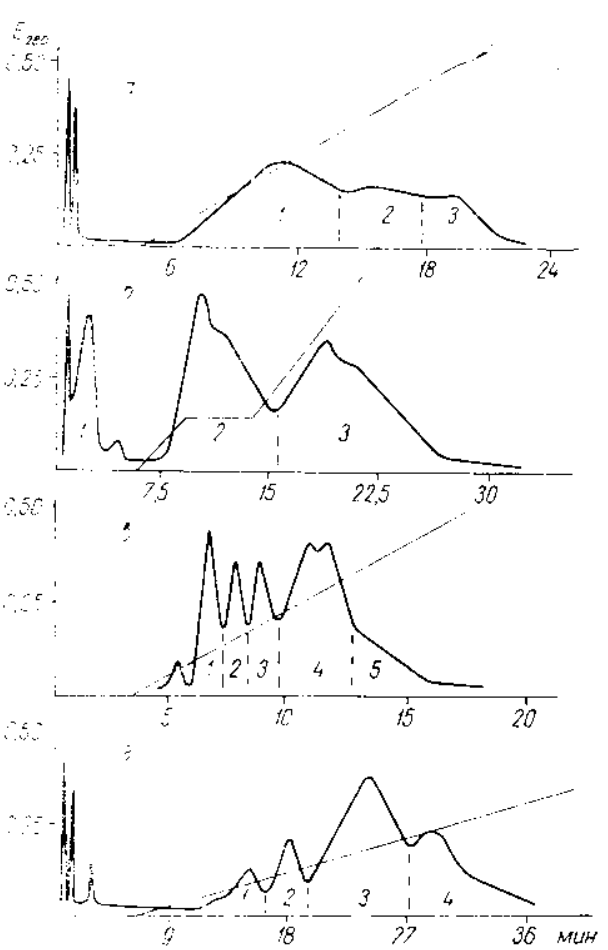
соотношение фрагментов BrCN6 и BrCN7 во фракции, нетрудно было ориентировочно подсчитать аминокислотный состав фрагмента BrCN7, который и приведен в табл. 1. Аминокислотный состав фракций III-4-3 и IV-2-2 различается только по содержанию гистидина. Поэтому мы предполагаем, что эти фракции включают одиі фрагмент BrCN9, содержащий гомосерин (III-4-3), и лактон гомосерина (IV-2-2). В табл. 1 приведен состав последнего.

C максимальным выходом $(25 \%)$ получен фрагмент BrCN6

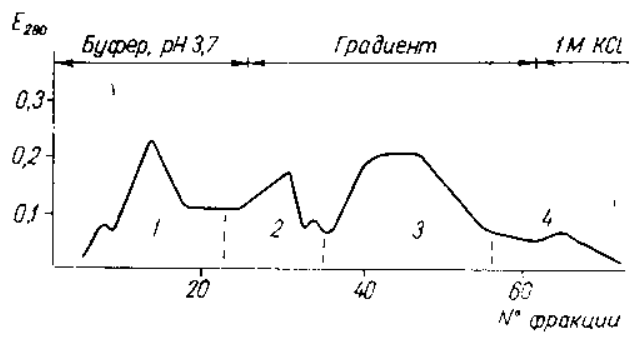

Рис. 5. ВЖХ в системе FPLC фракций I-B-2 (a), I-B-3 (б) (рис. 3, в) и III-3 (e), III-4 (2) (рис. 4, б). Колонка моноQ. Буфер и градиент см. «Материалы и методы» Fig. 5. FPLC - chromatography of fractions I-B-2 (a), I-B-3 (6) (Fig. 3, 8) and III-3 (6). III-4 (2) (Fig. 4, 6). Start-buffer $0.02 \mathrm{M}$ tris. HCl, pH 7.4, containing $6 \mathrm{M}$ urea. Linear gradient - start-buffer containing I $M \mathrm{KCl}$. Column monoQ

Рнс. 6. Разделение фракции II-1 (рнс. 4, a) на колонке $(1 \times 22$ см) с SP-сефадексом С-50. Буфер и градиент см. «Материалы и методы». Скорость элюции 12 мл/ч, объем фракции 5 мл

Fig. 6. Separation of fraction II-1 (Fig. 4, a) on a column (I $\times 22 \mathrm{~cm}$ ) with SP-sephadex C-50. Start-buffer pH 3.7 containing $6 \mathrm{M}$ urea. Concave gradient $-75 \mathrm{ml}$ of start-buffer and $75 \mathrm{~m}$ ! of start-buffer containing $0.5 \mathrm{M} \mathrm{KCl}$. Flow rate $-12 \mathrm{ml} / \mathrm{h}$, fraction volu. me $-5 \mathrm{ml}$

(фракция III-I, рис. 2). Эта фракция содержала фрагменты BrCN6 I BrCN7 в соотношении $4: 1$ соответственно, как было установлено электрофорезом в ПААГ (данные пе приведены). BrCN6 имел молекулярную массу 7000, а ВrCN7 - около 11000 . Выход фрагмента BrCN5 (фрағция П-3-с, рис. 2) составил $10 \%$. Молекулярная масса его, по данным электрофорсза в ПААГ, 8000. Выход фрагментов BrCN4 и $\mathrm{BrCN} 8$ не превышал $3 \%$. Этого количества хватило для расщепления трипсином, разделения полученных пептидов В/В электрофорезом на бумаге в одном электролите и определения аминокислотного состава триптических пептидов. Выход фрагментов BrCN1 - BrCN3 и BrCN9 составнл менее $1 \%$, что оказалось достаточным лишь для деградации по Эдману.

Ниже приведены результаты исследования первичной структуры каждого фрагмента. Аминокислотные составы пептидов, полученных при расщеплении ВrCN4 - BrCN8 трипсином (T) и химогрипсином (Ch), сведены в табл. 2. Стадии деградации по Эдману обозначены стрелкой под последовательностью. 
Т з 6 л и и д а 1

Aминокислотный состав бромциановых фрагментов каталазы $P$. vitale

The amino acid composition of cyanogen bromide fragments of $P$. vitale catalase

\begin{tabular}{|c|c|c|c|c|c|c|c|c|c|c|}
\hline \multirow[b]{2}{*}{$\begin{array}{l}\text { Амнно- } \\
\text { киелота }\end{array}$} & \multicolumn{9}{|c|}{ Состав фрагмевтов (фракции) } & \multirow[b]{2}{*}{$\underset{\text { ма }}{\text { Сум. }}$} \\
\hline & 趈官 & 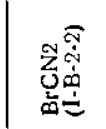 & 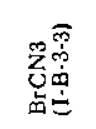 & 总突 & 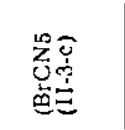 & 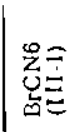 & 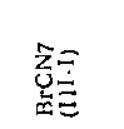 & 总点 & 藏 & \\
\hline Lys & - & $1,0(1)$ & $2,0(2)$ & $1,5(2)$ & $1,1(1)$ & - & $5,9(6)$ & $1,0(1)$ & - & 13 \\
\hline His & - & $0,7(1)$ & $0,7(1)$ & $1,0(2)$ & - & 3 & $2,0(2)$ & $0,9(1)$ & $1,4(2)$ & 10 \\
\hline Arg & - & $1,0(1)$ & $1,3(1)$ & $1,0(1)$ & $2,9(3)$ & 6 & $3,5(4)$ & $0,8(1)$ & - & 17 \\
\hline Asp & $1,0(1)$ & $3,8(4)$ & $3,6(4)$ & $5,0(5)$ & $10,0(10)$ & 10 & $12,3(12)$ & $3,9(4)$ & $1,8(2)$ & 52 \\
\hline Thr & $0,7(1)$ & $1,9(2)$ & $1,8(2)$ & $2,1(2)$ & $3,0(3)$ & 2 & $7,0(7)$ & $1,6(2)$ & - & 21 \\
\hline Ser & - & $2,0(2)$ & $1,6(2)$ & $3,7(4)$ & $7,0(7)$ & 1 & $6,7(7)$ & $0,7(1)$ & $1,0(1)$ & 25 \\
\hline Glu & $1,1(1)$ & $3,0(3)$ & $4,0(4)$ & $2,2(2)$ & $10,6(11)$ & 7 & $13,4(13)$ & $5,0(5)$ & $2,1(2)$ & 48 \\
\hline Pro & - & $1,2(1)$ & $1,0(1)$ & $6,0(6)$ & $6,0(6)$ & 6 & $3,5(4)$ & $2,0(2)$ & 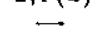 & 26 \\
\hline Gly & - & $2,0(2)$ & $2,6(3)$ & $2,9(3)$ & $4,8(5)$ & 7 & $9,0(9)$ & $2,0(2)$ & $1,0(1)$ & 32 \\
\hline Ala & - & $2,7(3)$ & $2,6(3)$ & $3,9(4)$ & $4.9(5)$ & 2 & $13,8(14)$ & $1,3(1)$ & $1,3(1)$ & 33 \\
\hline $\mathrm{Val}$ & $0,8(1)$ & $2,0(2)$ & $2,3(3)$ & $1,6(2)$ & $4,6(5)$ & 2 & $5,0(5)$ & $2,5(3)$ & $0,8(1)$ & 24 \\
\hline Ile & $1,9(2)$ & $1,0(1)$ & $2,0(2)$ & $1,4(2)$ & $2,8(3)$ & 3 & $2,5(3)$ & $1,2(1)$ & $0,8(1)$ & 18 \\
\hline Leu & $1,2(1)$ & $2,1(2)$ & $2,5(3)$ & $4,8(5)$ & $7,1(7)$ & 6 & $8,0(8)$ & $4,0(4)$ & $1,7(2)$ & 38 \\
\hline Туг & - & $0,5(1)$ & $0,7(1)$ & $1,7(2)$ & $2,0(2)$ & 1 & $1,3(2)$ & - & 78 & 0 \\
\hline Phe & - & $1,9(2)$ & 0.9 (1) & $1,0(1)$ & $4,7(5)$ & 4 & $2,9(3)$ & $1,6(2)$ & $0,9(1)$ & 19 \\
\hline H. Ser & - & - & 1 & - & - & 1 & (1) & - & - & 2 \\
\hline Bcero & 7 & 28 & 33 & 41 & 73 & $6 !$ & 100 & 30 & 14 & 387 \\
\hline $\mathrm{N}$-конец & Asp & Tyr & Leu & H. o. & Asp & Phe & H. 0 & H. о. & H. 0. & \\
\hline
\end{tabular}

П р и м е а н и е. Н. о. - N-конец не определяется.

$\Phi$ р аг м ен т BrCN1. Asp-Val-Ile-Ile-Glu- (Thr, Leu). Очевидно, что фрагмент получен в результате несиецифического по С-концу расщепления каталазы, скорее всего, до обработки ее бромцианом, так как известно, что при хранении каталаза подвергается частичной деграда12 11и $[10]$.

Фрагмент BrCN2. Tyr-(Lys, Arg, Asx 4 , $\mathrm{Thr}_{2}, \mathrm{Ser}_{2}, \mathrm{Glx}_{3}$, Pro, Gly, Ala, Val, Ile, $\left.\mathrm{Leu}_{2}, \mathrm{Phe}_{2}\right)$-H. Ser.

Та б.л и ц а 2

Аминокислотный состав триптических и химотриптических пептидов бромциановых ф):сінентов каталазы

Aritino acid composition of tryptic and chymotryptic peptides of $P$. vitale catalase (yltingen bromide fragments

\begin{tabular}{|c|c|c|c|c|c|c|c|c|c|}
\hline $\begin{array}{l}\text { Анино- } \\
\text { Бнслота }\end{array}$ & $\begin{array}{l}\text { 苟 } \\
\text { 品F }\end{array}$ & 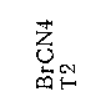 & 总 & 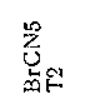 & 恣 & 总 & 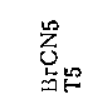 & 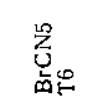 & 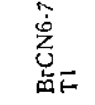 \\
\hline Lys & $1,3(1)$ & - & - & - & $1,2(1)$ & - & - & - & - \\
\hline His & - & - & - & $0 . \overline{5}(1)$ & 1, & - & - & - & $1,0(1)$ \\
\hline $\operatorname{lig}$ & 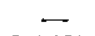 & - & $1,0(1)$ & - & - & $1,0(1)$ & - & - & $1.0(1)$ \\
\hline Asp & $2,1(2)$ & - & $0.9(1)$ & $5,8(6)$ & - & $2.3(2)$ & $1,6(2)$ & $1,0(1)$ & - \\
\hline Thr & $1,0(1)$ & - & - & $1,6(2)$ & - & $1,1(1)$ & - & - & - \\
\hline $\mathrm{Ser}$ & $0,8(1)$ & $1,0(1)$ & $0.9(1)$ & $2,1(2)$ & $0,8(1)$ & $1,0(1)$ & $1,4(2)$ & - & $\cdots$ \\
\hline Glu & $0,8(1)$ & - & $1,1(1)$ & $5.1(5)$ & - & $2,6(31$ & $2,0(2)$ & $1,0(1)$ & $1.2(1)$ \\
\hline Pro & $+(1)$ & - & - & $1.0(4)$ & $+(1)$ & $+(1)$ & $2,0(2)$ & 一 & $+(1)$ \\
\hline Gly & - & $1.0(1)$ & $1.2(1)$ & $2,3(2)$ & $1,1(1)$ & $1.7(2)$ & $2,3(2)$ & - & $1.4(1)$ \\
\hline $11 \mathrm{a}$ & $0,8(1)$ & - & $1,0(1)$ & $3.1(3)$ & - & $1.7(2)$ & $1,1(1)$ & $1,0(1)$ & - \\
\hline $\mathrm{Val}$ & - & - & - & $2,7(3)$ & - & $0,0(1)$ & $0,8(1)$ & $0,9(1)$ & $0, \bar{i}(i)$ \\
\hline Il: & - & - & - & $1.3(2)$ & - & $1,0(1)$ & $0.7(1)$ & $0,8(1)$ & $0,7(1)$ \\
\hline Ley & - & - & $2.1(2)$ & $2,0(2)$ & - & $2,0(?)$ & $0.8(1)$ & $2.2(2)$ & . \\
\hline Tyг & $1,0(1)$ & - - & - & $1.3\{2\}$ & - & - &..- & - & - \\
\hline $\mathrm{Ph}$ & - & --- & $2,0(2)$ & $2.0(2\}$ & - & $1, \vec{f}(2)$ & - & $1.0(1)$ & $0.8(1)$ \\
\hline H. SO: & -- & 一 & $\cdots$ & - & - & - & - & - & - \\
\hline B.ero & 9 & 2 & 10 & 36 & 4 & 19 & 14 & 8 & 8 \\
\hline
\end{tabular}


окончание табл. 2

\begin{tabular}{|c|c|c|c|c|c|c|c|c|c|}
\hline $\begin{array}{l}\text { Амнно- } \\
\text { кислота }\end{array}$ & 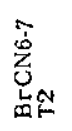 & 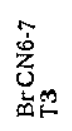 & $\begin{array}{l}\hat{\dot{S}} \\
\text { 它落 }\end{array}$ & 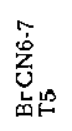 & $\begin{array}{l}J_{0} \\
\dot{U}_{\omega}\end{array}$ & 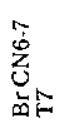 & 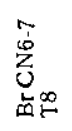 & 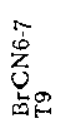 & 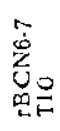 \\
\hline
\end{tabular}

\begin{tabular}{|c|c|c|c|c|c|c|c|c|c|}
\hline Lys & - & - & - & - & 一 & - & - & - & -_. \\
\hline His & - & - & $0,7(1)$ & $0,9(1)$ & 0,4 & & $1,2(1)$ & $1,1(1)$ & - \\
\hline Arg & $1,1(1)$ & $1,0(1)$ & $1,9(2)$ & $0,9(1)$ & - & $1,2(1)$ & 二 & $\therefore$ & - \\
\hline Asp & $2,1(2)$ & $1,9(2)$ & $2,1(2)$ & $3,3(3)$ & $1,0(1)$ & $0,7(1)$ & $0,9(1)$ & $1,0(1)$ & $1,0(1)$ \\
\hline Thr & $0,7(1)$ & $0,9(1)$ & - & - & - & - & $1,1(1)$ & - & $1,0(1)$ \\
\hline Ser & & $0,9(1)$ & - & - & - & - & - & 一 & $0,9(1)$ \\
\hline Glus & $2,0(2)$ & $1,1(1)$ & $1,9(2)$ & - & $1,2(1)$ & - & $1,6(2)$ & - & $1,4(1)$ \\
\hline Pro & $0,8(1)$ & - & $3,2(3)$ & $0,8(1)$ & r. & $+(1)$ & $+(1)$ & - & \\
\hline Gly & $1,9(2)$ & - & $1,7(2)$ & $\ldots$ & $1,8(2)$ & - & $3,0(3)$ & - & $1,0(1)$ \\
\hline Alá & - & - & - & $0,9(1)$ & $1,0(1)$ & - & - & - & $0,8(1)$ \\
\hline Val & $0,8(1)$ & - & - & - & - & - & $1,0(1)$ & - & $0,7(1)$ \\
\hline Ile & - & 一 & $0,9(1)$ & $0,9(1)$ & - & $1,0(1)$ & - & $1,0(1)$ & - \\
\hline Leu & $1,7(2)$ & $2,5(3)$ & $1,1(1)$ & - & - & - & - & - & $0,8(1)$ \\
\hline Туг & - & $1,0(1)$ & - & - & - & $\ldots$ & $0,7(1)$ & - & - \\
\hline Phe & $0,8(1)$ & $0,9(1)$ & $1,0(1)$ & - & - & - & - & - & - \\
\hline H. Ser & - & - & - & 一 & $0,3(1)$ & $0,9(1)$ & - & - & $0,5(1)$ \\
\hline Bcero & 13 & 11 & 15 & 8 & 6 & 5 & 11 & 3 & 9 \\
\hline
\end{tabular}

\begin{tabular}{|c|c|c|c|c|c|c|c|c|c|}
\hline $\begin{array}{l}\text { Амино- } \\
\text { кислота }\end{array}$ & 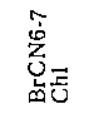 & 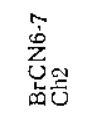 & 芯 & 总 & 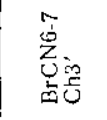 & 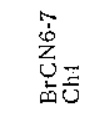 & 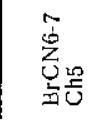 & 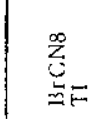 & 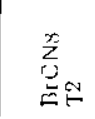 \\
\hline Lys & - & - & $\leftarrow$ & - & - & - & - & $0,8(1)$ & - \\
\hline $\mathrm{His}$ & $0,8(1)$ & $0,8(1)$ & $1,0(1)$ & $1,1(1)$ & $0,5(1)$ & - & - & - & - \\
\hline Arg & 1,0 (i) & $1,9(2)$ & $2,0(2)$ & $3,1(3)$ & $1,0(1)$ & $\ldots$ & - & - & - \\
\hline Asp & $1,3(1)$ & $1,0(1)$ & $1,0(1)$ & $4,9(5)$ & $3,8(4)$ & $2,0(2)$ & $2,0(2)$ & $2,4(2)$ & 0.4 \\
\hline Thr & - & - & - & - & - & $0,8(1)$ & - & $1,2(2)$ & $0,6(1)$ \\
\hline Ser & - & - & - & - & - & $0,6(1)$ & $0,8(1)$ & $1,3(1)$ & $1,3(1)$ \\
\hline Glu & $2,0(2)$ & - & 一 & $1,0(1)$ & $1,1(1)$ & $1,3(1)$ & $2,1(2)$ & $0,7(1)$ & $0,8(i)$ \\
\hline Pro & $1,2(1)$ & $3,2(3)$ & $2,8(3)$ & $2,5(3)$ & 二 & - & - & $+(1)$ & - \\
\hline Gly & $2,0(2)$ & $1,0(1)$ & - & $2,0(2)$ & $2,1(2)$ & - & $1,0(1)$ & $2,1(2)$ & $1,2(1)$ \\
\hline Ala & - & $1,0(1)$ & $1,1(1)$ & $2,0(2)$ & $1,0(1)$ & - & $1,1(1)$ & $0,8(1)$ & $0,7(1)$ \\
\hline Val & 一 & $\therefore$ & - & - & - & - & 1,0 (I) & $0,6(1)$ & $0,5(1)$ \\
\hline Ile & $1,1(1)$ & $1,0(1)$ & $1,0(1)$ & $0,8(1)$ & -- & - & - & - & - \\
\hline Leu & $1,0(1)$ & 二 & - & - & - & $2,0(2)$ & $\ldots$ & $2,6(3)$ & $0,5(1)$ \\
\hline Tyr & - & - & - & - & - & $0,7(1)$ & - & - & - \\
\hline Phe & $1,0(1)$ & $1,0(1)$ & - & - & - & - & - & $2,0(2)$ & - \\
\hline H. Ser & - & 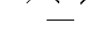 & - & $0,5(1)$ & $0,5(1)$ & - & - & $0,3(1)$ & $0,5(1)$ \\
\hline Bcero & 11 & 11 & 9 & 19 & 11 & 8 & 8 & 18 & 8 \\
\hline
\end{tabular}

Фр агмент BrCN3. Leu-Val-Asp-(Lys $2, A r g, A s x_{3}, \mathrm{Thr}_{2}, \mathrm{Ser}_{2}$, $\mathrm{Glx}_{4}$, Pro, $\left.\mathrm{Gly}_{3}, \mathrm{Ala}_{3}, \mathrm{Val}_{2}, \mathrm{Ile}_{2}, \overrightarrow{\mathrm{Leu}} \overrightarrow{2}, \overrightarrow{\mathrm{Tyr}}, \mathrm{Phe}\right)-\mathrm{H}$. Ser.

$\Phi$ р агм н т BrCN4. После расщепления трипсином и разделения В/В электрофорезом в электролите ЭФ2 были получены только два пептида. BrCN4Tl аналогичен по аминокислотному составу пептиду T14, строение которого установлено ранее [3]: Ala-Tyr-Ser-Asn-ThrGlu-Pro-Asn-Lys. BrCN4T2. На основании данных по аминокислотному составу (табл. 2) можно предположить, что пептид содержит не серин, а гомосерин, который иногда элюируется с колонки анализатора на месте серина. По-видимому, BrCN4T2 является С-концевым во фрагменте $\mathrm{BrCN} 4$.

$\Phi$ р аг м ен т BrCN5. После расщепления трипсином и разделення В/В электрофорезом в электролитах ЭФ1 и ЭФ2 были получены шесть пептидов, BrCN5T1. Leu-Phe-(Asp, Ser, Glu, Gly, Ala, Leu, Phe)-Arg. BrCN5T2 выделен в двух $\overrightarrow{\phi о р м а х ~-~ с ~ г и с т и д и н о м ~ и ~ б е з ~ н е г о . ~ М о ж н о ~}$ предположить, что в пептиде содержится не гистидин, а лактон гомосерина. В этом случае BrCN5T2 представляет собой С-концевой пептид фрагмента BrCN5. Из аминокислотных составов BrCN5T5 н 
BrCN5T6 (табл. 2) очевидно, что эти пептиды образовались в результате расщепления неспецифических для трипсина связей.

Ф р аг м е п ты BrCN6 и BrCN7. Как описано выше, эти фрагмен-

ты были получены в смеси и представлены во фракции III-I в соотношении $4: 1$ соответственно. Фракцию III-I расщепляли трипсином. Смесь пептидов разделяли В/В электрофорезом в электролитах $Э Ф 1$ и $Э Ф 2$ и хроматографией на бумаге. Были получены шесть пептидов (BrCN6-7T1- BrCN6-7T6) с выходом 10-25\% и четыре пептида (BrCN6-7T7-BrCN6-710) с выходом 1-7\%. BrCN6-7TI. Phe-Gln-ProGly-(His, Val, Ile)-Arg. BrCN6-7T2. Gly-Val-Asx-Phe-(Asx, $\overrightarrow{T h r}, \overrightarrow{\mathrm{G} l \mathrm{x}_{2}}$,

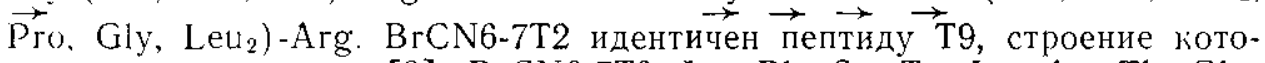
poro выяснено ранее [3]. BrCN6-7T3. Leu-Phe-Ser-Tyr-Leu-Asx-Thr-Glx-

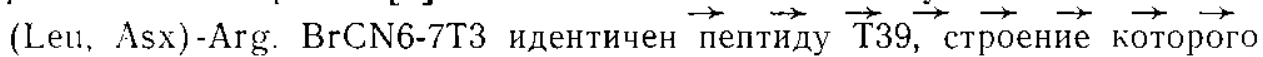
известно [3]. BrCN6-7T4. His-Gly-(Asn, Gln, Pro, Ile, Leu)-Gly-PheArg-Pro-(Pro, Asn)-Arg. Строение предложено на том основании, что этот пептид отличается по аминокислотному составу от пептида Т5 (частичное стросние которого установлено ранее [3]) только остатком гистидина. Возможно, пептид Т5 образовался в результате расщелления каталазы по остатку гистидина при обработке трипсином или в процессе хранения [10]. BrCN6-7T5. Ala-Pro-Ile-His-Asx-Asx-Asx-Arg. BrCN6-7T6. Acx-Gly-Ala-Gly-Glx-H. Ser. Очевидно, псптид содержит лактон гомосерина, а не остаток гистидина (табл. 2 ) и занимает С-концевое положение в одном из бромциановых фрагментов фракции III-I. BrCN6-7T8. Glx-Gly-Val-(Asx, Thr, Glx, Pro, Gly2, Tyr)-Lys. Из аминокислотного состава (табл. 2) ясно, что пептид BrCN6-7T10 представляет собої С-концевой участок второго бромцианового фрагмента, содержащегося во фракции III-I.

B результате расщепления смеси $\mathrm{BrCN6}-7$ химотрипсиіом были полумены семь пептидов. BrCN6-7Chl и BrCN6-7Ch4 выделсны с выходом около $20 \%$, остальные - 5\%. BrCN6-7Ch1. Arg-His-Gly-(Asx, Glx 2 , Pro, Gly, Ile, Leu, Phe), BrCN6-7Chl' отличается от BrCN6-7Ch1 наличием дополнительного остатка Asx, занимающего в нем N-концевое положсние. BrCN6-7Ch2. Gly-Phe-Arg-Pro-Pro-(Arg, His, Asx, Pro,

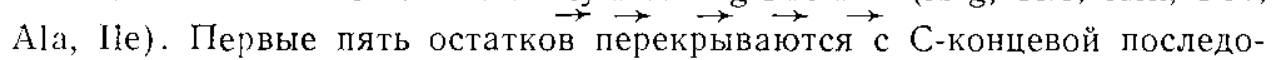
вательностью пептида BrCN6-7T4. Сравнивая составы и строение BrCN6-7Ch2 и BrCN6-7Ch2' (табл. 2) можно заключить, что меньший из іпи образовался при расщеплении связи Phe-Arg. BrCN6-7Ch3'. Asx-(Arg, His, Asx 3 , Glx, Gly, Ala)-H. Ser. Поскольку в пептиде имеет-

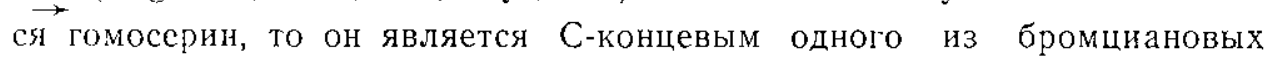
фрагментов фракции III-I. Исходя из некоторого сходства аминокислотных составов BrCN6-7Ch3' и BrCN6-7Ch3 (табл. 2), можно предноложить, что они образовались из одного и того же участка белка. BrCN6-7Ch4. Ser-(Asx 2 , Thr, Glx, Leu 2 , Tyr).

Мы предполагаем, что пептиды BrCN6-7T2, BrCN6-7T3, BrCN6-7T6, BrCN6-7Ch1, BrCN6-7Ch4, выделенные с максимальным выходом 20$25 \%$, получсны из одного мажорного фрагмента фракции III-I, обозначенного нами BrCN6.

На смеси BrCN6-7 провели 38 стадий деградации на ссквенаторе. На каждой из стадий, начиная с 1-й по 32 -ю, было идептифицировано по одному остатку аминокислоты. Следовательно, стуленчатой деградации подвергается один из фрагментов фракции III-I. У другого фрагмента $\mathrm{N}$-конец, по-видимому, блокирован. В установленную последовательность входят пептиды ВrCN6T2 и BrCN6T3. На этом основании мы считаем, что выясненная последовательность 32 остатков аминокислот принадлежит фрагменту BrCN6. Так как первые пять остатков пептида BrCN6-7Ch2 перекрываются с С-концевой последовательностью 
BrCN6-7T4, а пептиды BrCN6-7Ch3 и BrCN6-7Ch3', исходя из их амннокислотного состава (табл. 2), перекрывают последовательность BrCN6-7T4, BrCN6-7T5 и BrCN6-7T6, ясно, что все перечисленные пептиды также принадлежат фрагменту BrCN6.

Схема реконструкции фрагмента из фракции III-I приведена иа рис. 7. Триптические и химотриптические пептиды, не вошедшие в состав фрагмента BrCN6, мы относим к фрагменту BrCN7.
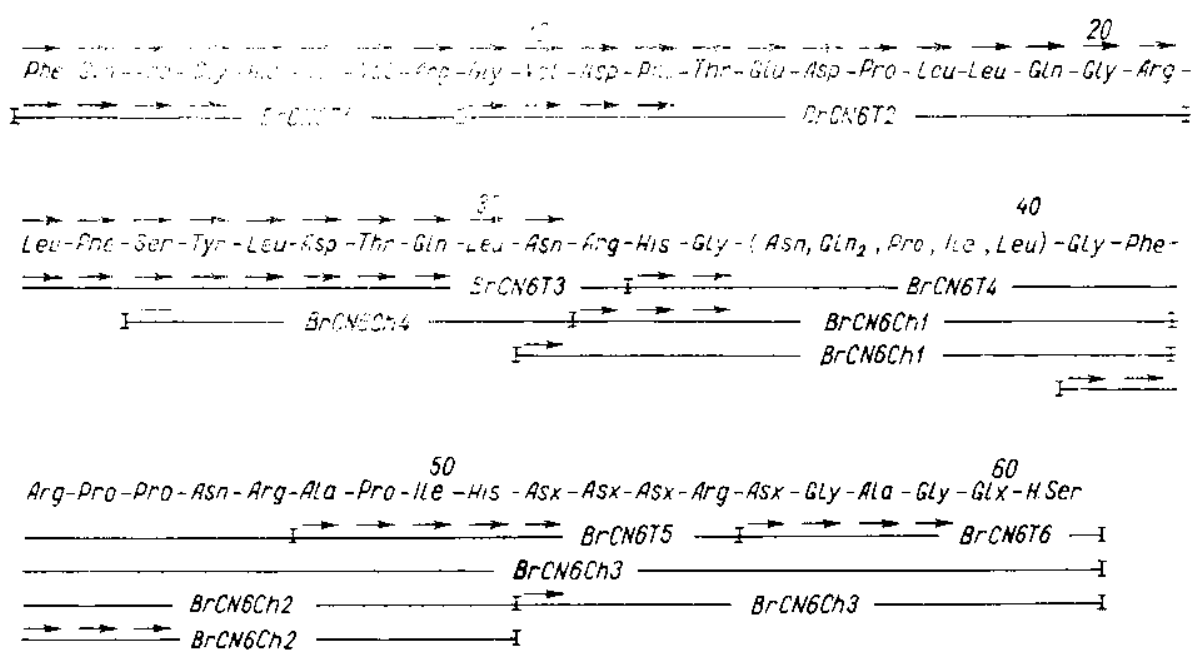

Рис. 7. Схема реконструкции полипептндной цепи фрагмента BrCN6 каталазы грнба $P$. vitale. Стрелками над последовательностью указаны стадии деградации по Эіману, проведенные на секвенаторе. Стрелками под последовательностью-деградация солтветствуюших пептидов по Эдману ручным методом

Fig. 7. Reconstruction of polypeptide chain of $P$. vitate catalase $\mathrm{BrCN} 6$ fragment. Arrows over amino acid sequence show Edman degradation steps estimated by the automat:c sequencer. Arrows under amino acid sequence show Edman manual degradation of the corresponding peptides

Ф р агмент ВrCN8. Iосле расщепления тринсином и разделения В/В электрофорезом в электролите ЭФ2 получены два пептида. Увеличенное содержание серина в них (табл. 2) можно объяснить наличием в одном пике остатков Ser и H. Ser. Присутствие в BrCN8T1 и BrCN8T2 остатка H. Ser свидетельствует о том, что оба пептида яв.ляются частью С-концевого участка фрагмента $\mathrm{BrCN8}$. Вычитая из аминокислотного состава BrCN8T1 состав BrCN8T2, получим аминокисдотный состав пептида Т31, строение которого установлено ранее [3]: Phe-Gly-Phe-Asp-(Pro, Leu)-Leu-Thr-Asp-Lys. Интересно отметить, что состав BrCN8T2 очень сходен с таковым BrCN7T10 (см. выше). Можно :толагать, что фрагмент BrCN8 входит в состав фрагмента BrCN7 и прецставляет собой его С-концевую часть.

Ф par мен т BrCN9. Gin-(His, Asx, Ser, Glx , Gly, Ala, Val, lle, Leu $_{z}$, Phe)-II. Ser. Этог фрагмент не подвергается ступенчатой деградацин. Можно полагать, что на $\mathrm{N}$-конце BrCN9 расположен остаток Gln, зациклизовавшийся в пирролидонкарбоновую кислоту в процессе выделения фрагмента.

Таким образом, из продукта расщепления каталазы бромцианм выделены девять фрагментов, насчитываюших в сумме 387 остатков аминокислот. Установлена полная аминокислотная последовательность участка нолипегтидной цепи каталазы, включающего 61 остаток аминкислот, и частичная аминокислотная последовательность двух участКов, вклюуающих в сумме 37 остатков.

Сравнивая первичную структуру фрагмента BrCN6 с аминокислотной последовательностью каталазы печени быка [11], мы обнаружили в этом белке участок 333-393, гомологичный фрагменту (степень го- 
мологии $54 \%$ ). Ниже приведено сравнение участков двух ката.таз в однобуквенном обозначении:

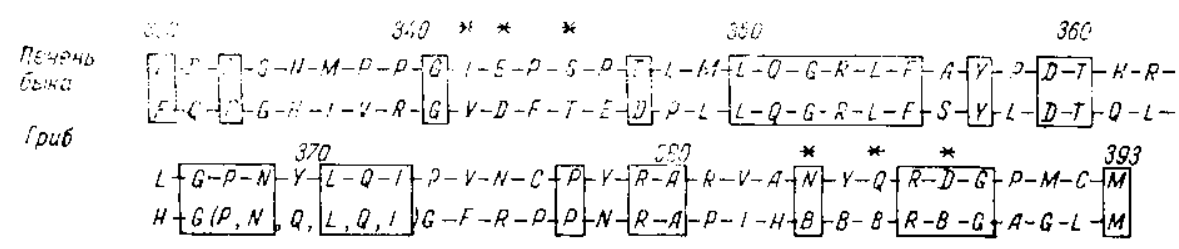

При расчете степени гомологии, кроме идентичных остатков аминокислот (28 остатков, взятых в рамки), мы учитывали и нейтральные замены Val $\rightarrow$ Ile, $A s p \rightarrow$ Glu, Thr $\rightarrow$ Ser, Asn $\rightarrow$ Gln (шесть замен, обозначениых звездочкой). В последовательности каталазы грнба остатки аминокислот внутри скоб́ки расставлены по принципу наио́.пьшей гомологии, а в положениях 384,386 и 388 неидентифицированные ос. татк! Asx yсловно приняты за Asn, Asn и Asp соответственно.

Авторь балгодаря Э. Л. Ким (Нн-т молекуляр. биологин и тенетикн АН УССР) за техническую помощь при разделении смеси фрагмснтов в системе FPLC и В. М. Харченко (ИМБиГ АН УССР) - за проведенис анализв аминокислотного состава.

\section{СПИСОК „ТТТЕРАТУРЫ}

1. Триптия'ки пептиды каталазы гриба Penicillium vitale. 1. Разделение и амино-

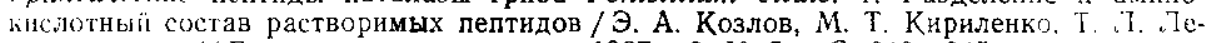
нитина и др. // Бнополимеры и клетка.-1987.-3, № 5.- С. 240-245.

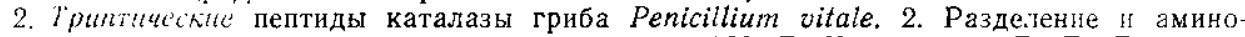
кислотный состав нерастворимых пептидов / М. Т. Кириленко, Т. Т. Тевнтина, Л. В. Гудкова и др.// Там же.- 1988.-4, № 1.-C. $40-43$.

3. Триптические пептиды каталазы гриба Penicillum vitale. 3. Строение некоторых пептидов / Н. М. Гусак, Т. Л. Левитина, С. А. Атепалихина и др. // Биополнмеры н клетка.- 1989.-5, № 1.- C. $45-52$.

4. Cross K., Wilkop B. Nonenzymatic cleavage of peptide bonds: the methionine residu. es in bovine pancreatic ribonuclease //J. Biol. Chem.-1962.-237, N 6. - P. 18561865 .

5. Лурье Ю. Ю. Справочник по аналитической химии.-М. : Химия, $1971 .-454$ с

6. Кавсан В. М., Мороз Л. В., Серебряный С. Б. Прнспособление для горизонта.tьного электрофореза на бумаге упрощенной конструкции $/ /$ Укр. бнохим. журн.-1968. 40, № 1 . - C. $104-106$.

7. Steank R. T., Munkers K. D. Molecular weight analysis of oligopeptides by ciectrophoresis in polyacrylamide gel with sodium dodecyl-sulfate//Anal. Birctron.$1971 .-39, \mathrm{~N} 2 .-$ P. $462-477$.

8. Oпределение структуры пептидов комбинированным методом дансил- 3 јан $t$ Н. М. Гусак, М. Н. Овандер, Л. Б. Дробот, С. Б. Серебряный // Методы молекуяр. бнологин.- Киев : Наук. думка.-1979.- С. $142-154$.

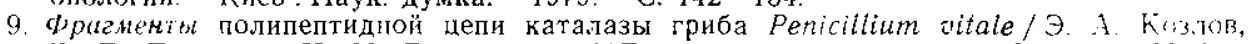
Т. Л. Левитина, Н. М. Гусак и др.//Биополимеры и клетка.-- 1987.-3, $\therefore$. 6. C. $318-320$.

10. Denis $C$., Roger H., Colin $M$. Proteolytic modification oi mouse liver catajase $/$ Biochem. and Biophys. Res. Communs. - 1982.-104, N 4.- P. 1567-1572.

11. The complete amino acid sequence of bovine liver catalase and partial sequerce of bovine erythrocyte catalase / W. A. Schroeder, J. R. Shelton, L. B. Sheiton et a!. /. Arch. Biochem. Biophys.- : $982 .-214$, N $1 .-$ P. $397-421$.

Ин-т молекуляр. биологии и генетики АН УССР, Қиев

Ин-т бнохимии им. А. В. Палладина АН УССР, Киев

Голуген, 33.95 .88 


\section{CYANOGEN BROMIDE FRAGMENTS OF PENICILLIUM VITALE CATAL $A$ SE}

T. L. Levitina, N. M. Gusak, N. V. Rodnin, M. T. Kirilenko,

O.S. Miroshnichenko, S. A. Atepalikhina, L. V. Gudkova, E. A. Kozlov

Institute of Molecular Biology and Genetics,

A. V. Palladin Institute of Biochemistry,

Academy of Sciences of the Ukrainian SSR, Kiev

$\mathrm{S} u \mathrm{~mm}$ a r $\mathrm{y}$

Nine fragments containing 387 amino acid residues were isolated from product of cyanogen bromide treatment of $P$. vitale catalase by Sephadex gel-filtration, ion-exchange chromatography, butanol extraction and high-voltage paper electrophoresis. Tryptic, chymotryptic peptides and $\mathrm{N}$-terminal sequence of some $P$. vitale catalase cyanogen bromide fragments were investigated. Complete and partial amino acid sequences of fragments including 61 and 37 amino acid resudies, respectively, were determined.

УдК 577.113 .4

\section{Ю. В. Пацковский, Т. П. Волощук, А. И. Потопальский \\ НЕКОТОРЫЕ ОСОБЕННОСТИ РЕАКЦИИ ПОЛИНУКЛЕОТИДОВ С ТИОФОСФАМИДОМ}

В работе проводили изучение направлений алкилирования нуклеиковьх кислот противоопухолевым агентом тиофосфамидом, а также этиленимином и моноазиридиндиэтилфосфатом. Показано, ито степень алкилирования гомополирибонуклеотидов определяется природой гетерочиклических оснований в их составе, что свидетельствует о преимущественном алкилировании остатков азотистых оснований. Методом обращенно-фазовой высокоэффективной онидкостной хроматографии выделейы продукты алкилирования и показано, что алкилирование рибонуклеозидов в свободном виде и в составе полинуклеотидов производньли этиленимина происходит в основном по $\mathrm{N} 7$ положению ауанозина, по N1 - аденозина и по N3- пиримидиновьх нуклеозидов. Уменьшение значений рН и ионной силь средь приводит к увеличению скорости алкилирования ДНК.

Введение. Тиофосфамид, или тиотэф,- - трифункциональный алкилирующий агент, обладающий противоопухолевым действием [1]. Противоопухолевая активность обнаружена также у ДНК, алкилированной гиотэфом [2]. Предполагается, что биологическая активность тиотэфа, как и других электрофильных алкилирующих агентов, обусловлена его взаимодействием с клеточной ДНК [3]. Однако доказательства, полученные к настоящему времени, достаточно противоречивы и носят, в основном, косвенный характер. На примере реакции алкилирования этиленимином и тиотәфом мононуклеотидов показано, что алкилироваmие происходит в основном по остаткам фосфсрной кислоты [4]. С другой стороны, результаты, полученные авторами работы [5], свидетельствуют об алкилировании метилированных аналогов оснований нуклеиновых кислот тиотэфом в водной среде. Изменение физико-химических свойств ДНК вследствие алкилирования (денатурация, фрагментация, изменение плотности отрицательного заряда, изменение спсктральных характеристик) подтверждает возможность модификации нуклеофнльных центров в ДНК $[2,6,7]$. Однако при этом неясно, какие нуклеофильные центры в составе нуклеиновых кислот и в каких условиях оказываются предпочтительными в реакции алкилирования остатки гетероциклических оснований или остатки фосфорной кислоты. В связи с этим мы решили выяснить основные направления алкилирования пуклеозидов и полинуклеотидов производными этиленимина тиотэфом и моноазиридиндиэтилфосфатом.

Материалы и методы. $\mathrm{N}, \mathrm{N}^{\prime}, \mathrm{N}^{\prime \prime}$-триэтиленимид тиофосфорной кислоты (тиотэф, I) синтезирован по мстоду [8], моноэтиленимид диэтилового эфира фосфорной кислоты 